\title{
Spermatozoa and spermatogenesis in the northern quahaug Mercenaria mercenaria (Mollusca, Bivalvia)
}

\author{
Xue-Ping Ying • Wan-Xi Yang • \\ Hans-U. Dahms $\cdot$ Zhihua Lin $\cdot$ Xueliang Chai
}

Received: 6 December 2007 / Revised: 28 May 2008 / Accepted: 4 June 2008 / Published online: 26 June 2008

(C) Springer-Verlag and AWI 2008

\begin{abstract}
We studied the ultrastructure of spermatogenesis and spermatozoa in the northern quahaug, the clam Mercenaria mercenaria. Spermatogenetic cells gradually elongate. Mitochondria gradually fuse and increase in size and electron density. During spermatid differentiation, proacrosomal vesicles migrate towards the presumptive anterior pole of the nucleus and eventually form the acrosome. The spermatozoon of M. mercenaria is of a primitive type. It is composed of head, mid-piece, and tail. The acrosome shows a subacrosomal space with a short conical contour. The slightly curved nucleus of the spermatozoon contains fine-grained dense chromatin. The middle piece consists of a centriolar complex which is surrounded by four mitochondria. The flagellum has a standard " $9+2$ " microtubular structure. The ultrastructure of spermatozoa and spermatogenesis of M. mercenaria shares a number of features with other species of the family Veneridae. M. mercenaria may
\end{abstract}

Communicated by H.-D. Franke.

\section{X.-P. Ying}

School of Biological and Environmental Sciences,

Wenzhou University, 325027 Wenzhou, China

W.-X. Yang $(\bowtie)$

Department of Biology, College of Life Sciences,

Zhejiang University, 310012 Hangzhou, Zhejiang, China

e-mail: wxyang@spermlab.org

H.-U. Dahms

Institute of Marine Biology,

National Taiwan Ocean University,

2 Pei-Ning Road, Keelung 202, Taiwan

Z. Lin $\cdot$ X. Chai

Zhejiang Mariculture Research Institute,

325005 Wenzhou, China be a suitable model species for further investigations into the mechanisms of spermatogenesis in the Bivalvia.

Keywords Mercenaria mercenaria .

Reproductive biology $\cdot$ Spermatogenesis .

Spermatozoa $\cdot$ Testis $\cdot$ Ultrastructure

\section{Introduction}

Spermatozoa of bivalve Mollusca generally belong to a morphologically primitive type (Franzen 1983; Hodgson and Bernard 1986; Dorange and Le Pennec 1989; Healy 1995; De Rosa et al. 2003; Suwanjarat 1999; Deng and Tan 2000; Dai et al. 2004; Sun et al. 2000; Zhu and Yang 2004). Different types of spermatozoa can be distinguished among taxonomic groups. The morphology of bivalve spermatozoa can even be species-specific and often provides useful characters for phylogenetic reconstructions (Popham 1974; Franzen 1983; Hodgson and Bernard 1986; Healy 1995). The examination of sperm structure is thus of significance for the reproductive biology as well as for phylogenetic reconstructions.

There have been several studies on the ultrastructure of spermatozoa in the Bivalvia (Franzen 1983; Healy 1995; Reunov and Hodgson 1994; Suwanjarat 1999; Keys and Healy 1999; Du 1996; Sun et al. 2000; Liu et al. 1990; Guo and Tan 2002; Guerra et al. 2003; Zhu and Yang 2004; Ren et al. 1998). However, there are only a few studies on the ultrastructure of spermatogenesis and spermatozoa of members of the family Veneridae (Zeng and Li 1991; Reunov and Hodgson 1994; De Rosa et al. 2003; Nicotra and Zappata 1991; Healy 1995; Guo and Tan 2002), and no investigations on spermatozoa or spermatogenesis at the ultrastructural level as yet. The Veneridae is an economically 
important bivalve family since several representatives are marketed as shell fish.

Mercenaria mercenaria is commonly known as the northern quahaug. It belongs to the family Veneridae in the class Bivalvia. It is a shellfish of high nutritional value, originating from the Atlantic coast of North America and introduced to China in 1997. The use of this species for aquaculture in China has led to investigations on its basic reproductive biology, ecological habits, metabolism, artificial breeding, and mariculture (Lin et al. 2002, 2005; Zhang et al. 2003; Wen et al. 2004). In the present study we describe the ultrastructure of the spermatozoa and characterize the stages of spermiogenesis in M. mercenaria by transmission electron microscopy. The aim of the study was to reveal the basic features of the different spermatogenic stages, and to provide information useful for analysing phylogenetic relationships among Veneridae and other bivalves.

\section{Materials and methods}

The specimens of $M$. mercenaria were collected, on a monthly basis, from April to July in 2004 and from March to April in 2005 from the Zhejiang Mariculture Research Institute. Samples of testes were obtained, from five individuals each, which showed different degrees of gonad maturation at similar length. Small pieces of testes $(<1 \mathrm{~mm})$ were fixed in $2.5 \%$ glutaraldehyde in phosphate buffer $(\mathrm{pH}$ 7.4) and post fixed in $1 \%$ osmium tetroxide in phosphate buffer. After dehydration in alcohol, specimens were embedded in Spurr resin 618. Ultrathin sections were cut by a Sweden LKB 2088 ultramicrotome equipped with a diamond knife, and then stained with uranyl acetate and lead citrate. Thin sections were observed using a JEOL JEM-1200EX transmission electron microscope.

\section{Results}

Gonads of mature male M. mercenaria show germ cells in various stages of spermatogenesis. The ultrastructure of spermatogonia, spermatocytes, spermatids, and mature spermatozoa were identified and described as follows.

\section{Spermatogonia}

Spermatogonia are located in the peripheral region of the follicles. They are derived from primitive germ cells by mitotic division and differentiation. Spermatogonia are oval or irregular in shape (Fig. 1). Some spermatogonia remain as spermatogenic stem cells, while others undergo the process of spermatogenesis. The latter have spherical or oval

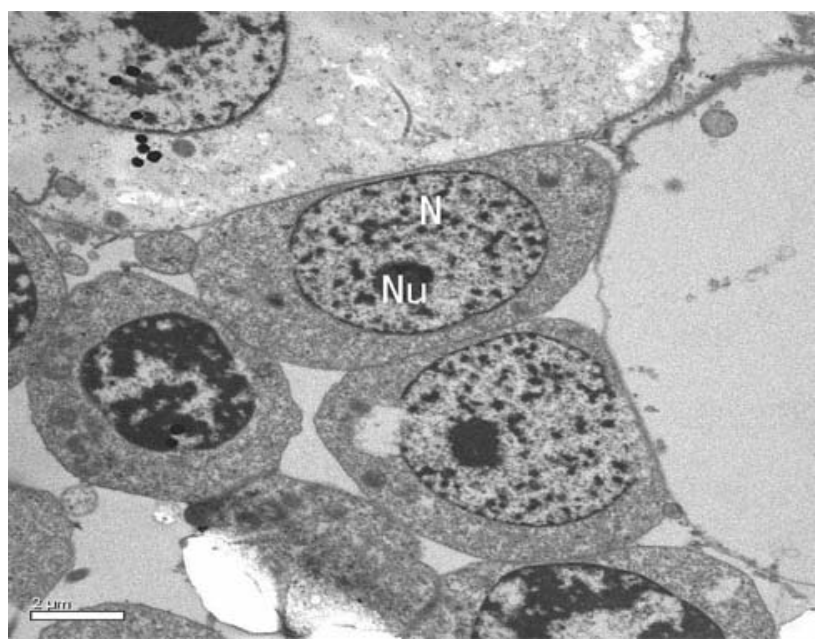

Fig. 1 Early stage spermatogonium; nucleus $(N)$, nucleolus $(N u)$; bar $2 \mu \mathrm{m}$

nuclei (Fig. 2) and small patches of heterochromatin scattered throughout the nucleoplasm. The small cytoplasm contains only a few cytoplasmic organelles, including Golgi vesicles and mitochondria (Figs. 1, 2).

\section{Primary spermatocytes}

Primary spermatocytes are derived by mitotic division from spermatogonia. Thus their number is much higher than that of the spermatogonia. The cytoplasm has increased in volume. There are scattered agglomerations of chromatin in the nucleus and the organelles in the cytoplasm have significantly increased in number. Numerous endoplasmic reticular vesicles are present, and the electron density and cristae in the mitochondria have increased (Fig. 3).

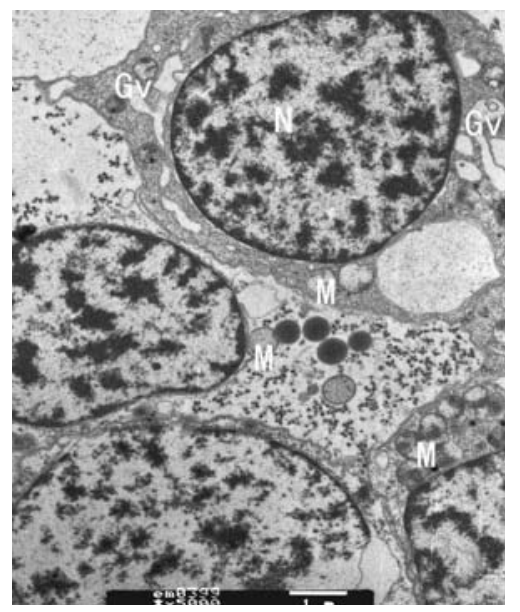

Fig. 2 Late stage spermatogonium; nucleus $(N)$, Golgi vesicle $(G v)$, mitochondria $(M)$; bar $1 \mu \mathrm{m}$ 


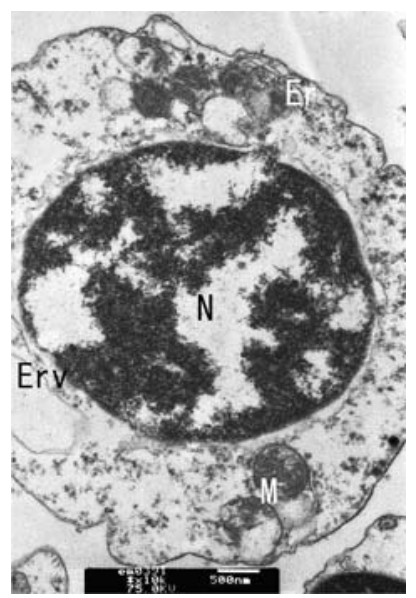

Fig. 3 Primary spermatocyte; increased mitochondria $(M)$, endoplasmatic reticulum $(E r)$, and endoplasmatic reticulum vesicle (Erv); bar $500 \mathrm{~nm}$

\section{Secondary spermatocytes}

Primary spermatocytes undergo the first meiotic division, leading to secondary spermatocytes with a chromosome number split to half (Fig. 4). In the cytoplasm, there are some electron dense vesicles and vacuoles, the mitochondria significantly increase in both number and size, and their cristae increase in number as well. The mitochondria gradually concentrate on one side and contribute to the cell's polar appearance (Fig. 5).

\section{Spermatids}

Spermatids derive from secondary spermatocytes undergoing the second meiotic division. Then, spermatids differentiate into mature spermatozoa. Among spermatids, early, intermediate, and late stages can be distinguished. These differ with respect to the condensation of nuclei, the development

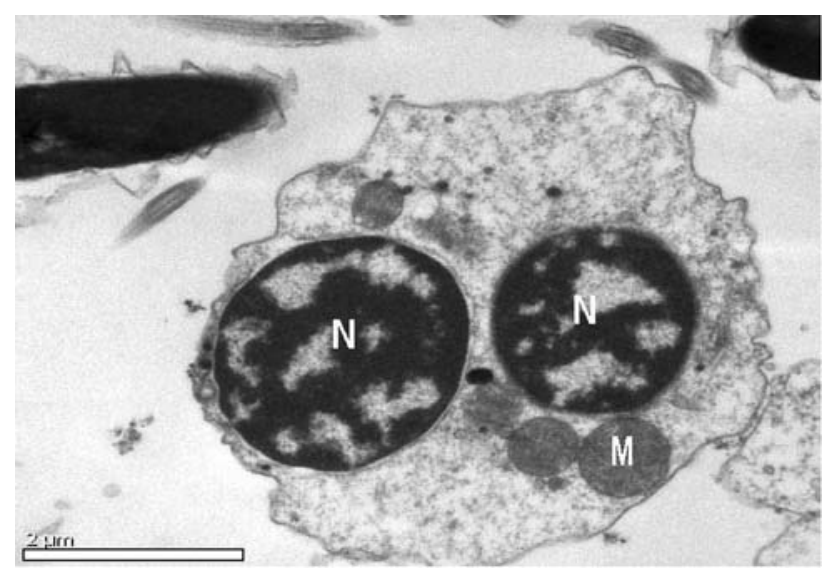

Fig. 4 Two-nucleus stage spermatocyte; mitochondria $(M)$, nucleus $(N)$; $\operatorname{bar} 2 \mu \mathrm{m}$

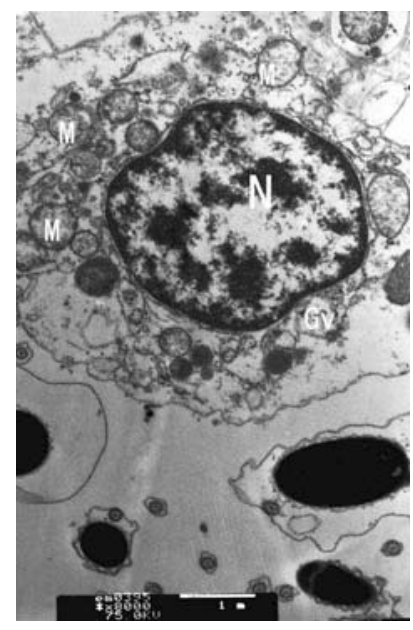

Fig. 5 Secondary spermatocyte, with polar concentration of nucleus $(N)$ and mitochondria $(M)$; bar $1 \mu \mathrm{m}$

of mitochondria and Golgi bodies, the formation of the acrosome, and the development of the mid-piece.

Early stages of spermatids

Early spermatids are irregular in shape; show a large spherical nucleus and a nuclear chromatin beginning to condensate. The cytoplasm of the spermatids in this stage has fewer electron transparent areas, and the chromatin densities are far lower than those of secondary spermatocytes (Fig. 6). The cytoplasm shifts to the presumptive posterior pole of the nucleus, while the Golgi vesicles move to the presumptive anterior pole of the nucleus. The condensation of chromatin is uniform throughout the nucleus (Fig. 7). Mitochondria concentrate on one side of the cell and begin to fuse. The Golgi vesicles subsequently fuse to form proacrosomal vesicles (Fig. 8).

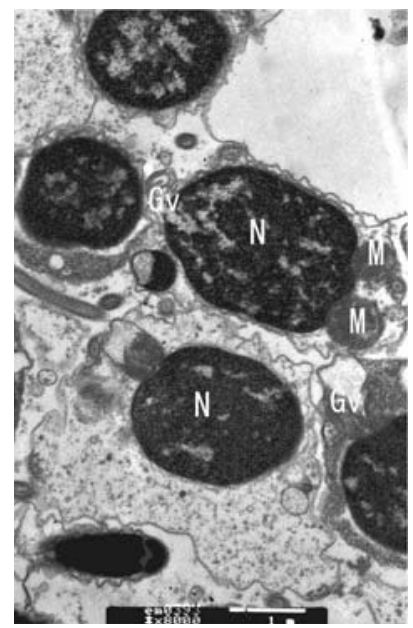

Fig. 6 Early stage spermatid with condensed chromatin and aggregated Golgi vesicles $(G v)$, mitochondria $(M)$; bar $1 \mu \mathrm{m}$ 


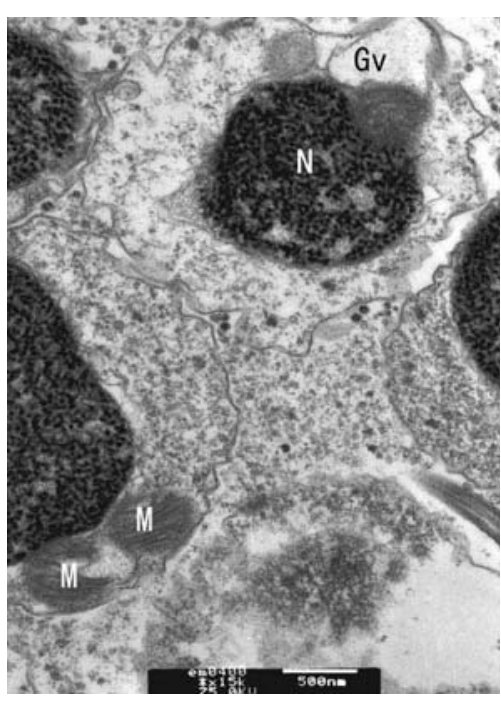

Fig. 7 Early stage spermatid with Golgi vesicles $(G v)$ aggregating at the top of the nucleus, mitochondria $(M)$; bar $500 \mathrm{~nm}$

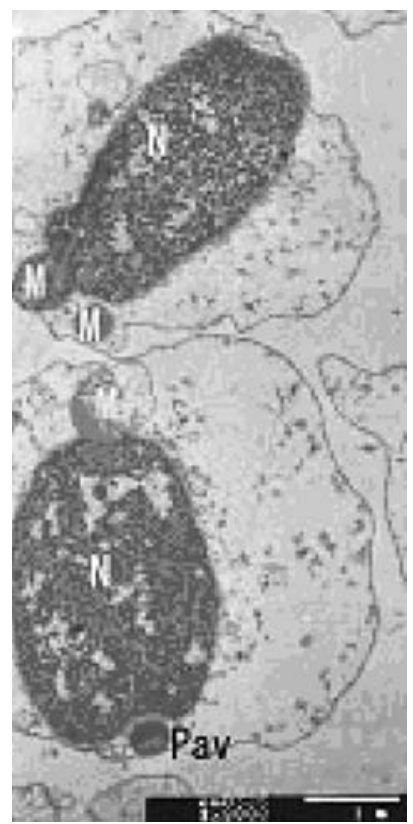

Fig. 8 Early stage spermatid with pre-acrosomal vesicles $(P a v)$ and mitochondria $(M)$, both alongside the elongated nucleus $(N)$; bar $1 \mu \mathrm{m}$

Intermediate stages of spermatids

In intermediate stages, the chromatin transforms from a dispersed state into fine fibrillar threads at or close to the center of the nucleus, and to thick fibrillar threads laterally, which elongate and orientate longitudinally along the nuclear axis (Figs. 9, 10). Proacrosomal vesicles develop from particulate matter and form a proacrosome (Fig. 9). The mitochondria aggregate further, fuse, and finally form a large

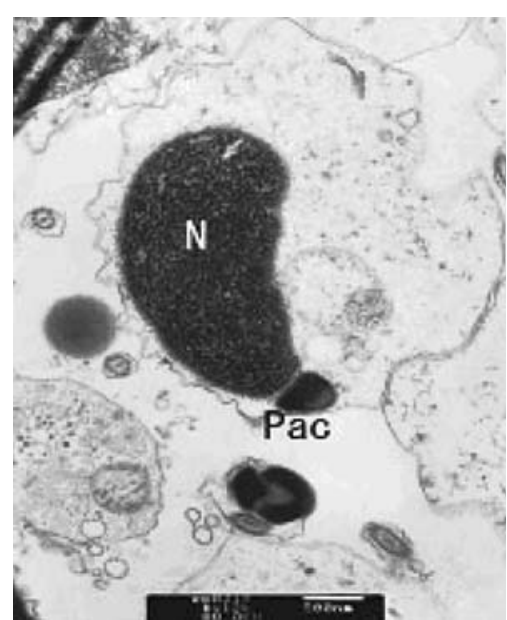

Fig. 9 Intermediate stage spermatid with elongated nucleus $(N)$ and pre-acrosome (Pac); bar $500 \mathrm{~nm}$

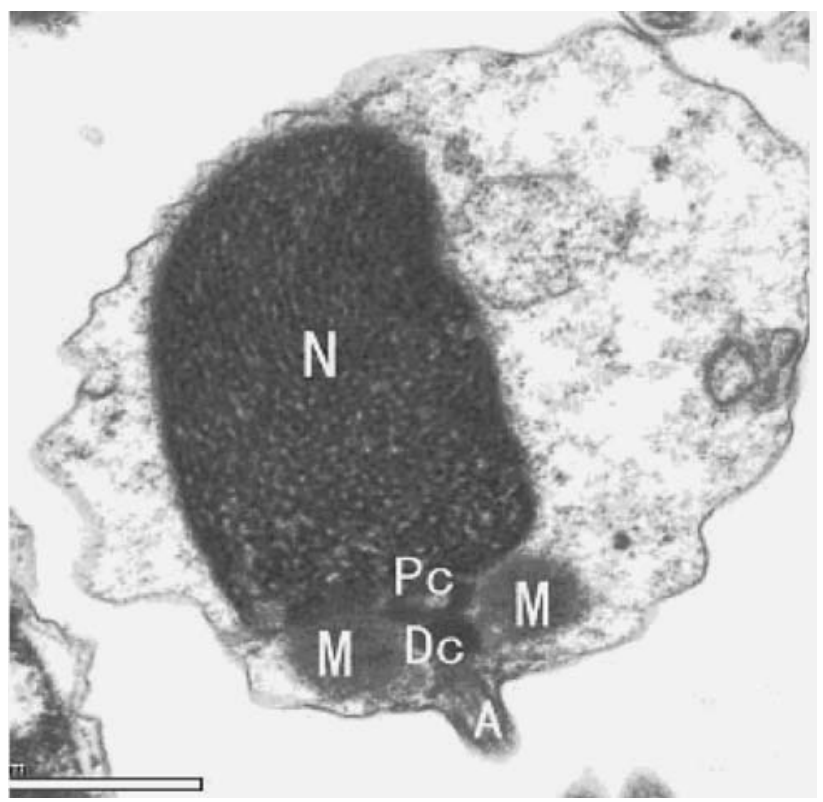

Fig. 10 Intermediate stage spermatid; elongated nucleus $(N)$ with granular chromatin, mitochondria $(M)$, distal centriole $(D c)$, proximal centriole $(P c)$, axoneme $(A)$; bar $1 \mu \mathrm{m}$

mitochondrial cluster, which gradually shifts to the posterior pole of the nucleus. During this stage, the axoneme appears and gets surrounded by mitochondria (Fig. 10).

Late stage of spermatid development

In the late stage of spermatid development, the nucleus elongates along with the proacrosomal vesicles, centrioles, and mitochondrial axes. The chromatin continues to condensate and the nucleus finally becomes homogeneous and electron dense (Fig. 11). The prominent giant mitochondria begin to aggregate at the base of the nucleus and eventually associate 


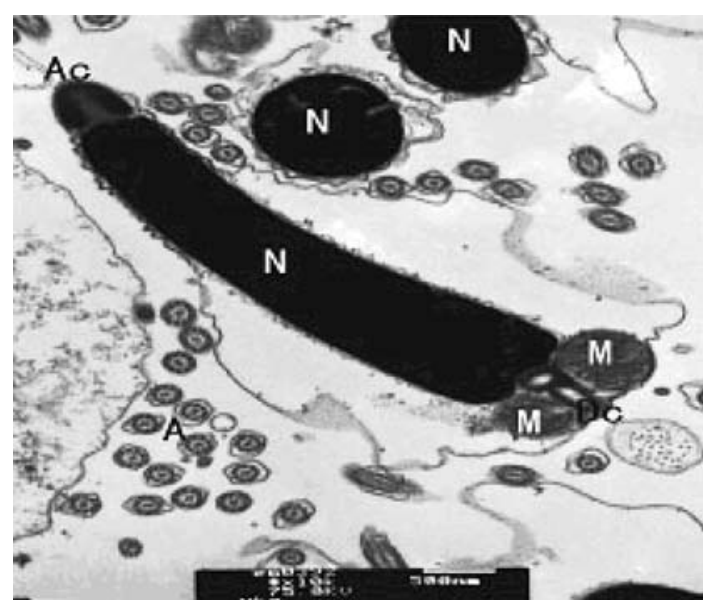

Fig. 11 Late stage spermatid; nucleus $(N)$, acrosome $(A c)$, subacrosomal space $(S s)$; bar $500 \mathrm{~nm}$

closely with the developing flagellar axoneme (Fig. 11). The proacrosomal vesicles fuse to form an acrosomal vesicle. This vesicle increases in size and develops into a single large acrosome (Figs. 11, 12). The inner side of the acrosome becomes concave; the subacrosomal space contains dense granular material (Figs. 12, 13). During acrosome formation, the shape of the entire sperm changes and the sperm tail differentiates (Fig. 14). Finally, spermatids abandon some cytoplasm and form the mature sperm (Fig. 15).

The ultrastructure of sperm

The fully mature spermatozoon of M. mercenaria is of a primitive type, consisting of three distinct regions: head,

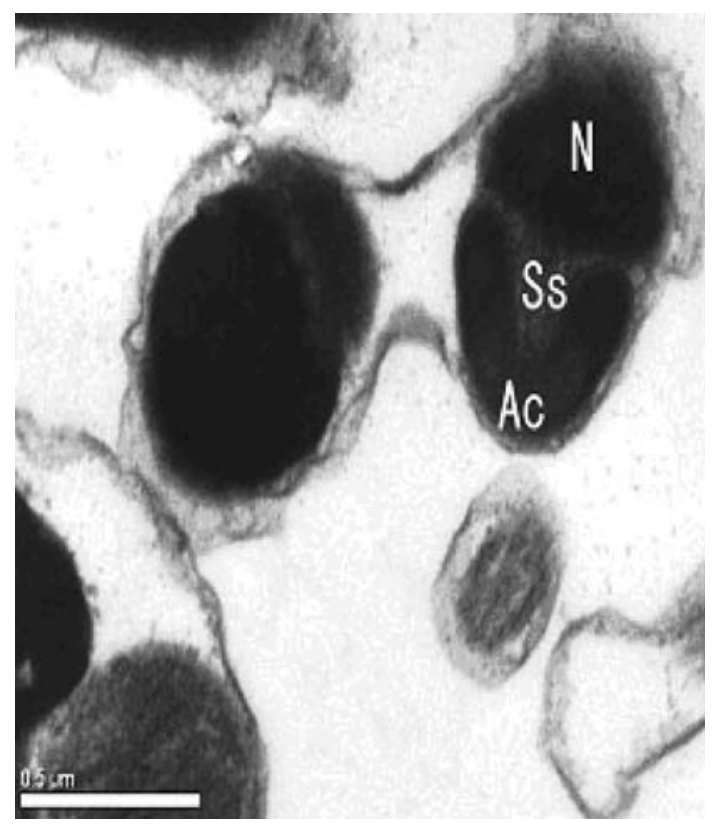

Fig. 12 Longitudinal section of acrosome (Ac); bar $0.5 \mu \mathrm{m}$

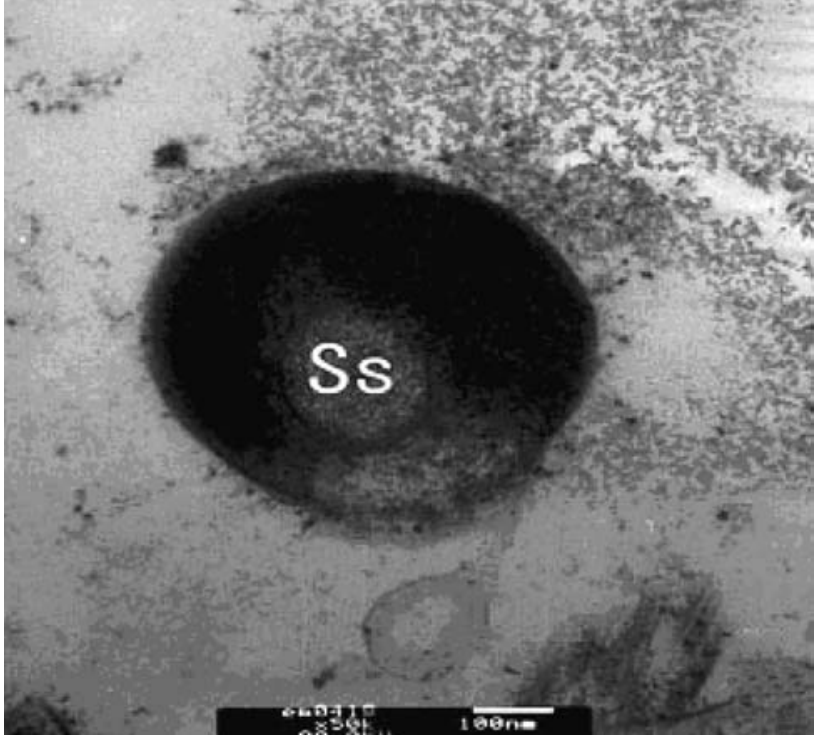

Fig. 13 Transverse section of acrosome (Ac), subacrosomal space (Ss); bar $100 \mathrm{~nm}$

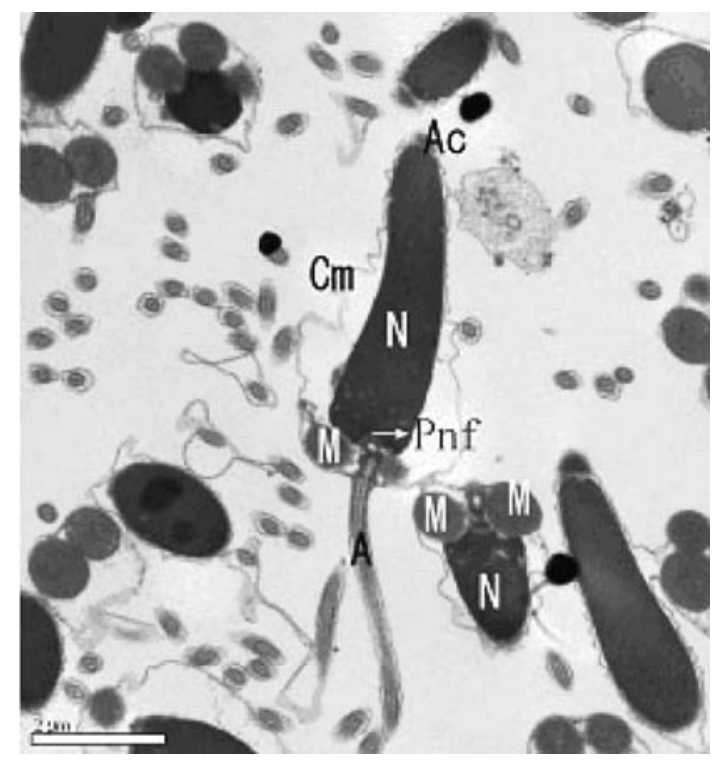

Fig. 14 Longitudinal section of sperm showing head, mid-piece and axoneme $(A)$, cell membrane $(\mathrm{Cm})$, posterior nuclear fossa $(P n f)$; bar $2 \mu \mathrm{m}$

mid-piece, and flagellum (Fig. 15). The head region is composed of nucleus and acrosome at the anterior tip. The nucleus is cylindrical and slightly curved. Their content is highly electron-dense (Fig. 16). The anterior end of the nucleus, which is close to the acrosome, is flattened, whereas its posterior end is invaginated, forming a nuclear pocket (Fig. 17). The acrosome is cap-shaped, with $0.6 \mu \mathrm{m}$ in length and $0.4 \mu \mathrm{m}$ in maximum diameter at the base. The acrosomal vesicle is invaginated at its base, almost as deep as the height of the acrosome. This invagination is filled with granular subacrosomal material (Fig. 15). The mid-piece 


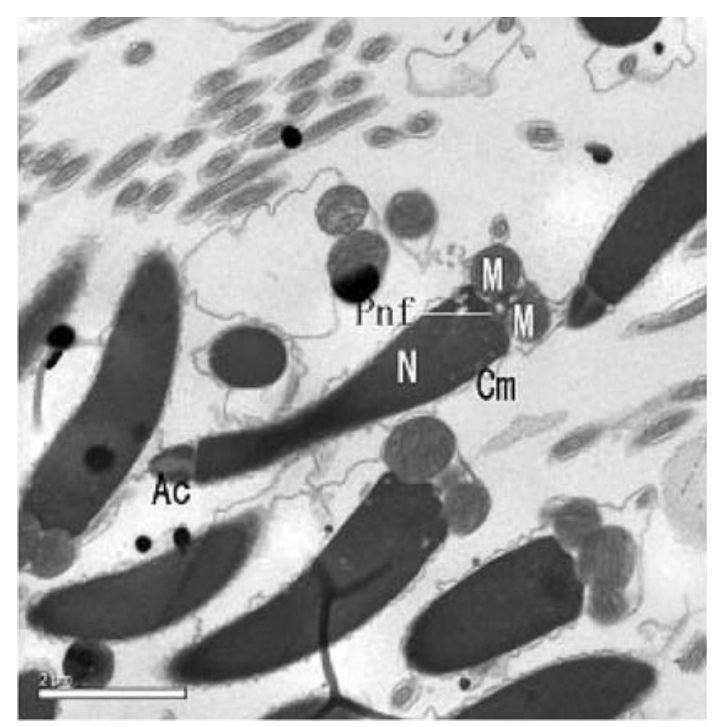

Fig. 15 Longitudinal section of sperm, showing acrosome $(A c)$, nucleus $(N)$, posterior nuclear fossa $(P n f)$, mitochondria $(M)$, proximal centriole $(P c)$, and distal centriole $(D c)$; bar $2 \mu \mathrm{m}$

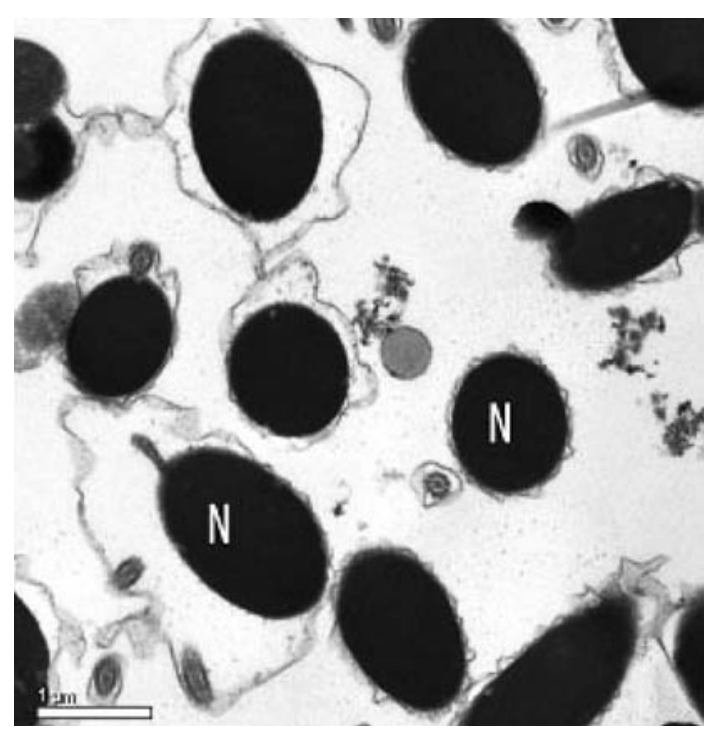

Fig. 16 Transverse section of spermatozoal nucleus $(N)$; bar $1 \mu \mathrm{m}$

region consists of four giant mitochondria with well developed cristae, arranged in a ring with two centrioles in the center (Fig. 18). Two spherical mitochondria can be seen at the level of a longitudinal section of the mid-piece. The proximal centriole is embedded into a posterior nuclear pocket, while the distal one gives rise to a sperm flagellum (Fig. 15). The microtubular arrangement of the sperm flagellum is of regular axoneme pattern: a central pair of microtubules is surrounded by nine doublets, which in turn are surrounded by an undulating plasma membrane. The axoneme ends where the flagellum tapers off (Figs. 19, 20).

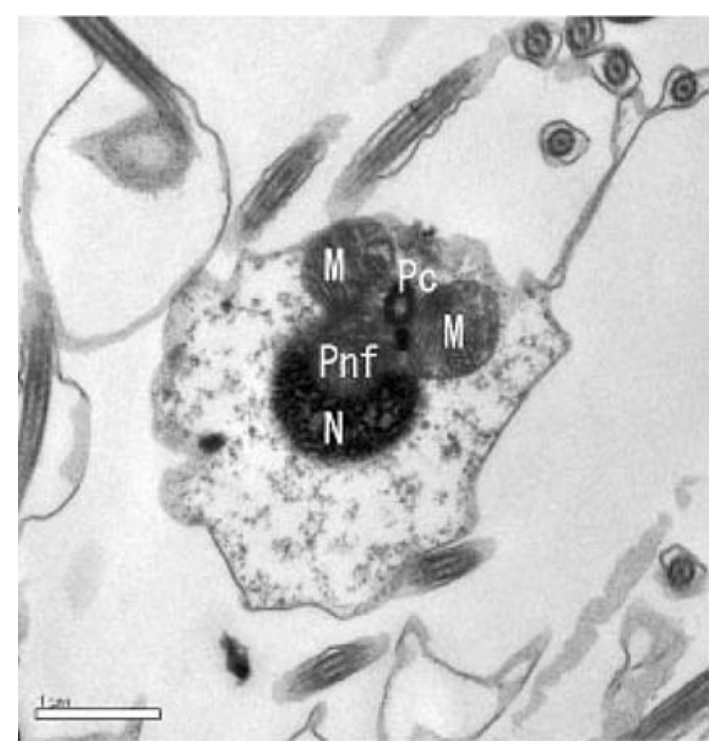

Fig. 17 The oblique section of mid-piece of spermatid, showing posterior nuclear fossa $(P n f)$, proximal centriole $(P c)$ and mitochondria $(M)$; bar $1 \mu \mathrm{m}$

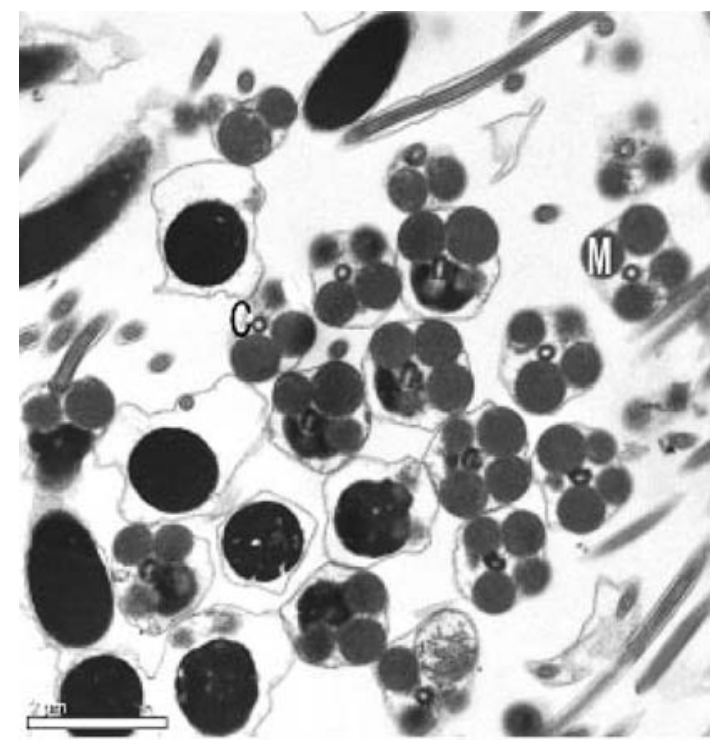

Fig. 18 Transverse section of mid-piece of mature sperm, showing ring of four spherical mitochondria $(M)$ around a centriole $(C)$; bar $2 \mu \mathrm{m}$

\section{Discussion}

The spermatozoon of M. mercenaria is of a primitive type. Primitive sperm are generally developed in species that spawn their gametes freely into the water where fertilization occurs. Most bivalves including M. mercenaria belong to this group of free-spawners. 


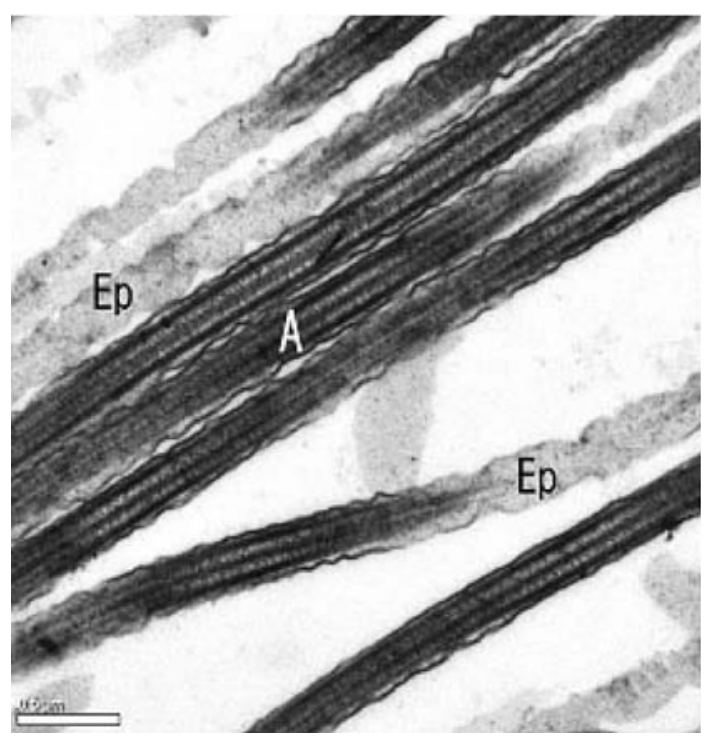

Fig. 19 Longitudinal section through axoneme $(A)$ tapering to electron-dense filamentous end-pieces (Ep); bar $0.5 \mu \mathrm{m}$

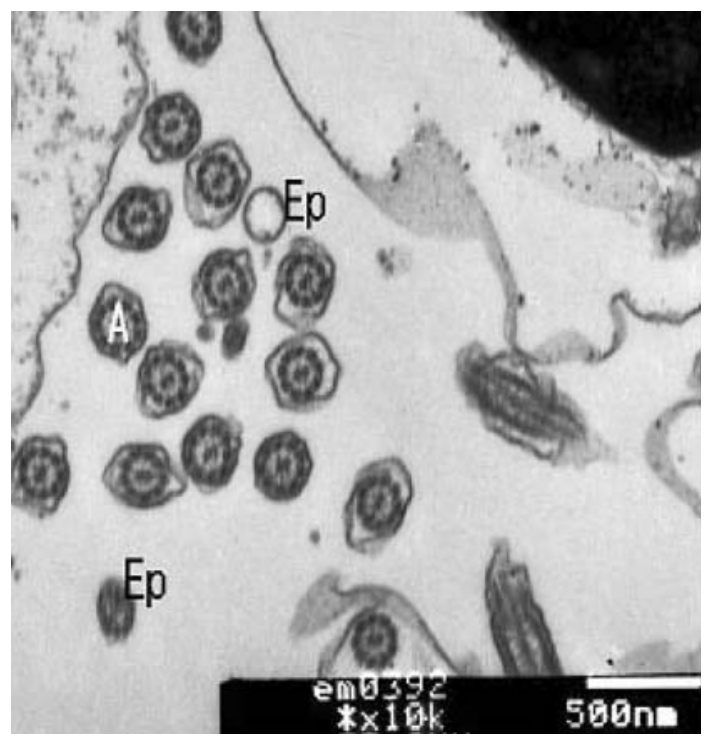

Fig. 20 Transverse section of axoneme (A); bar $500 \mathrm{~nm}$

Nucleus and acrosome

The changes of the nucleus include extreme chromatin condensation and a change in nuclear shape. When spermatids differentiate to form sperm, the nucleus volume is reduced due to chromatin condensation, and spermatids get streamline in shape which makes their movement more efficient and reduces energy losses during fertilization. Walker (1970) suggested that there are three basic chromatin condensation patterns: granular, fibrous, and lamellate. In the reproductive cells of $M$. mercenaria the chromatin of the nucleus develops from a dispersed state over coarse granules and fibrillar threads to compact homogeneous granules. This is similar to the sequence observed in Cyclina sinensis (Zeng and Li 1991), Paphia undulate (Zhao and Li 1992), Ruditapes philippinarum (Dai et al. 2004) and Mytilus edulis (Guo and Tan 2002).

Nuclei of bivalve sperm are usually spherical or ovoid (Suwanjarat 1999; Dong et al. 2005; Deng and Tan 2000; Ren et al. 1998), but in several venerid bivalves, they are elongated and curved (Nicotra and Zappata 1991; Gwo et al. 2002; Reunov and Hodgson 1994; Zeng and Li 1991). The mature sperm nucleus of M. mercenaria is cylindrical and slightly curved, and it is similar to some species of Veneridae in having its anterior end flattened, whereas it's posterior end is invaginated, forming nuclear pockets. Franzen (1983) suggested that elongated nuclei belong to the primitive form in bivalves, and that their occurrence may be correlated with large, yolk-rich eggs that require a deeper penetration of the sperm. Such nuclear shape is very common in the sperm of Veneridae (Healy 1995). However, its specific function in this family is still unknown.

Acrosome morphology varies in diagnostically important ways in the Bivalvia, especially in the Veneridae (Morse and Zardus 1997; Healy 1995). Franzen (1983) suggested that acrosomal morphology could be correlated with differing functional needs of fertilization in bivalves. Most sperm acrosomes of marine bivalve species are long and slender or else short and blunt, and the structure of the subacrosomal space is different as well (Popham 1979; Franzen 1983; Hodgson and Bernard 1986; Deng and Tan 2000; Ren et al. 1998; Zeng and Li 1991). In several species, the subacrosomal substance is organized into a more or less completely preformed acrosomal filament or axial rod (Popham 1979; Liu et al. 1990). The axial rod in the acrosome seems to lengthen during the acrosome reaction in some bivalve spermatozoa (Franzen 1983). In the oyster Saccostrea commercialis, the subacrosomal material comprises an axial rod embedded in a coarsely granular matrix (Healy and Lester 1991). In Pinctada maxima, the acrosome shows a lamellar structure (Du 1996), which was interpreted as a more advanced step possibly related to internal fertilization. In other species, the subacrosomal substance polymerizes during the acrosome reaction (Suwanjarat 1999). In the sperm of freshwater mussels, there are only several little acrosome vesicles and a typical acrosomal structure seems to be absent (Eduardo and Azevedo 1990; John 1994; Guo and Tan 2002). The acrosome of M. mercenaria is short and tapered. Between acrosome and nucleus there is a dense subacrosomal substance which is scattered in front of the acrosome's deep hollow, and no axial rods are found. The acrosome of M. mercenaria is thus similar to those of other Veneridae species (Healy 1995; Gwo et al. 2002) and of Amusium pleuronectes and Anadara granosa (Suwanjarat 1998, 1999). 
In Veneridae, proacrosomal vesicles were described as derived from Golgi vesicles during the pachytene phase of the meiosis in Tivela polita (Reunov and Hodgson 1994) or during spermiogenesis in Callista chione (Nicotra and Zappata 1991). Conversely, in Eurhomalea rufa, proacrosomal vesicles, although appearing during the pachytene stage as well, are the product of both the Golgi complex and the rough ER (De Rosa et al. 2003). The proacrosome vesicle of M. mercenaria is also derived from Golgi vesicles of the spermatocyte, which form the proacrosome during the spermatid differentiation. The ER appears in small densities during the spermatogenesis of M. mercenaria. Whether the ER joins the Golgi complexes to form the proacrosome remains unknown as yet.

\section{Mitochondria and centrioles}

In the mature sperm of the primitive type, the middle piece contains a number of large mitochondria which are probably formed by fusion of several smaller ones. In bivalves, the number of mitochondria in the midpiece generally ranges from four to six (Healy 1995). Sinonovacula constricta shows four to six mitochondria (Liu et al. 1990). Mature sperm of Laternula limicola, Cyclina sinensis, Tegillaca granosa, and some freshwater mussels generally have five mitochondria (Kubo and Ishikawa 1978; Zeng and Li 1991; Sun et al. 2000; Eduardo and Azevedo1990; John 1994; Guo and Tan 2002; Deng and Tan 2000). Whereas the middle piece of sperm in Veneridae typically shows five mitochondria (Reunov and Hodgson 1994; Nicotra and Zappata 1991), in M. mercenaria we only found four, arranged in a ring with two centrioles in its center. This observation conforms to those on the venerids Pitar rudis and Chamelea gallina by Erkan and Sousa (2002). Thus, four mitochondria seem to be common in Veneridae as well, just as in most bivalve species (Popham 1974, 1979; Franzen 1983; Dorange and Le Pennec 1989; Keys and Healy 1999; Suwanjarat 1998; Du 1996; Ren et al. 1998; De Rosa et al. 2003; Zhao and Li 1992). However, bivalves belonging to the Mytilidae have 14 mitochondria (Drozdov and Reunov 1986), and the majority of the Cardiidae have seven to nine (Healy 1995). The number of mitochondria in the middle piece of mature spermatozoa varies among bivalve species, but is specific of a given species.

In the primitive sperm of most molluscs, both centrioles are conserved. At the beginning of spermiogenesis, they are positioned at right angles to each other, the proximal one being oriented perpendicular to, and the distal one in line with, the axoneme. The distal centriole forms the basal body of the flagellum (Morse and Zardus 1997). Deviations from this general pattern are sometimes encountered. For example, in the mature sperm of the bivalve Lyonosia ventricosa, the proximal centriole moves to the lateral side of the distal one in such a way that the two become situated in parallel (Kubo and Ishikawa 1978). In M. mercenaria, the centrioles are positioned at right angles and situated in the posterior area of the nucleus. The distal centriole begins to form a flagellum in the spermatocyte.

\section{Flagellum}

In molluscs, the sperm typically has one flagellum. The axoneme within the flagellum normally consists of a central pair of microtubules surrounded by nine doublets. A few deviations from this general pattern have been reported in mollusks (Suwanjarat 1999). The flagellum of M. mercenaria shows a typical axonemal complex of $9+2$ microtubules. In most cases, the plasma membrane wrapping the axoneme is undulating (Fig. 19). Such pattern is found in Cyclina sinensis, Chlamys farreri and several other bivalves (Zeng and Li 1991; Ren et al. 1998).

From the present study it becomes apparent that M. mercenaria shares common features of primitive spermatozoa. There is substantial variation in shape and dimension of acrosome vesicles and nuclei in Veneridae providing diagnostic characters at the species and genus levels. Our results support the suggestion that the morphology of bivalve spermatozoa can add valuable characters for taxon discrimination and phylogenetic reconstructions (Reunov and Hodgson 1994; Healy 1995).

Acknowledgment This work was supported in part by the following projects: National Natural Science Foundation of China (No. 30671606), Key Project of Sci-Technology Bureau of Zhejiang Province (No. 011102104) and Project from the Education Bureau of Zhejiang Province (No. 20051293).

\section{References}

Dai PF, Rao XZ, Chen YS (2004) Ultrastructural studies on spermatozoon and spermatogenesis of Ruditapes philippinarum. Chin $\mathrm{J}$ Zool 39:26-32

De Rosa M, Zarrilli S, Paesano L, Carbone U, Boggia B, Petretta M, Maisto A, Cimmino F, Puca G, Colao A, Lombardi G (2003) Traffic pollutants affect fertility in men. Hum Reprod 18:10551061

Deng DG, Tan QK (2000) Ultrastructural studies of spermatogenesis of the fresh-water mussel, Cristaris plicata (Bivalva, Unionidae). Acta Hydrobiol Sin 25:63-66

Dong QX, Huang CJ, Tiersch TR (2005) Spermatozoal ultrastructure of diploid and tetraploid Pacific oysters. Aquaculture 39:115-125

Dorange G, Le Pennec M (1989) Ultrastructural characteristics of spermatogenesis in Pecten maximus (Mollusca, Bivalvia). Invertebr Reprod Dev 15:109-117

Drozdov AL, Reunov AA (1986) Spermatogenesis and the sperm ultrastructure in the mussel Modiolus dicilis. Tsitologiya 28:1069-1074

Du XD (1996) Studies on the ultrastructural changes in spermatogenesis of Pinctada maxima Jameson. J Wuhan Univ (Natural Science Edition) 42:219-224 
Eduardo R, Azevedo C (1990) Ultrastructure study of the spermatogenesis of Anodonta cygnea L. (Bivalvia, Unionidae). Invertbr Reprod Dev 18:3169-3176

Erkan M, Sousa M (2002) Fine structural study of the spermatogenic cycle in Pitar rudis and Chamelea gallina (Mollusca, Bivalvia, Veneridae). Tissue Cell 34:262-272

Franzen A (1983) Ultrastructural studies of spermatozoa in three bivalve species with notes on evolution of elongated sperm nucleus in primitive spermatozoa. Gamete Res 7:199-214

Guerra R, Sousa M, Torres A, Oliveira E, Baldaia LT (2003) Fine structure of acrosome biogenesis and of mature sperm in the bivalve molluscs Glycymeris sp. (Pteriomorphia) and Eurhomalea rufa (Heterodonta). Helgol Mar Res 57:7-12

Guo YP, Tan QK (2002) Ultrastructural studies on spermatogenesis of the fresh water mussel, Hyriopsis cumingii. Chin J Zool 37:2-5

Gwo JC, Yang WT, Sheu YT (2002) Spermatozoan morphology of four species of bivalve (Heterodonta, Veneridae) from Taiwan. Tissue Cell 34:39-43

Healy JM (1995) Comparative spermatozoal ultrastructure and its taxonomic and phylogenetic significance in the bivalve order Veneroida. In: Jamieson BGM, Ausio J, Justine J-L (eds) Advances in spermatozoal phylogeny and taxonomy. Mem Mus Natn Hist Nat, Paris, 166: 55-166.

Healy JM, Lester RJG (1991) Sperm ultrastructure in the Australian oyster Saccostrea commercialis (Iredale and Roughley) (Bivalvia: Ostereoidea). J Moll Stud 57:219-224

Hodgson AN, Bernard RTF (1986) Ultrastructure of the sperm and spermatogenesis of three species of Mytilidae (Mollusca, Bivalvia). Gamete Res 15:123-135

John WL (1994) The ultrastructure of the sperm and motile spermatozoa released from the freshwater mussel Anodonta grandis (Mollusca, Bivalvia, Unionidae). Can J Zool 72:1452-1461

Keys JL, Healy JM (1999) Sperm ultrastructure of the giant clam Tridacna maxima (Tridacnidae:Bivalvia:Mollusca) from the Great Barrier Reef. Mar Biol 135:41-46

Kubo M, Ishikawa M (1978) Organizing process of the temporary acrosome in spermatogenesis of the bivalve Lyonosia ventricosa. J Submicrosc Cytol 10:411-421

Lin ZH, Cai XL, Fan J (2002) An aptitude test on the environmental habits of Mercenaria mercenaria. J Ningbo University (Ness) 15:19-22

Lin ZH, Shan LZ, Cai XL (2005) The reproductive biology of hard clam Mercenaria mercenaria (Linnaeus, 1758). Chin J Oceanol Limnol 36:430-436
Liu ZC, Shangguan BM, Xu ZZ (1990) On the ultrastructural features of spermatogenesis of the razor clam, Sinonovacula constricta (Lamarck). J Xiamen Univ (Natural Science) 29:81-84

Morse MP, Zardus JD (1997) Bivalvia. In: Harrison FW, Kohn AJ (eds) Microscopic anatomy of invertebrates, vol 6: Mollusca II. Wiley, New York, pp 89-95

Nicotra A, Zappata S (1991) Ultrastructure of the mature sperm and spermiogenesis in Callista chione (Mollusca, Bivalvia). Invert Reprod Dev 20:213-218

Popham JD (1974) Comparative morphometrics of the acrosome of the sperm of "externally" and "internally" fertilizing sperms of the shipworms (Teredinidae, Bivalvia, Mollusca). Cell Tissue Res 150:291-297

Popham JD (1979) Comparative spermatozoon morphology and bivalve phylogeny. Malacol Rev 2:1-20

Ren SL, Wang RC, Wang DX (1998) Ultrastructure of spermatozoon of the Chlamys farreri. J Ocean Univ Qindao 28:387-391

Reunov AA, Hodgson AN (1994) Ultrastructure of the spermatozoa of five species of South African bivalves (Mollusca), and an examination of early spermatogenesis. J Morphol 219:275-283

Sun HL, Fang JG, Wang QY (2000) Ultrastructure of the spermatozoon of Tegillaca granosa. J Fish China 24:297-301

Suwanjarat J (1998) TEM study of the Asian moon scallop (Amusium pleuronectes) spermatogenesis. J Electron Microsc Soc Thail 12:95-104

Suwanjarat J (1999) Ultrastructure of the spermatogenesis of the cockle Anadara granosa L. Helgol Mar Res 53:85-91

Walker MH (1970) Some unusual features of the sperm of Nucella lapillus (L.). In: Bacetti B (ed) Comparative spermatology. Academic Press, New York, pp 383-391

Wen HX, Zhang T, Yang HS (2004) Effect of temperature on respiration and excretion of hard clam Mercenaria mercenaria (Linnaeus, 1758). Chin J Oceanol Limnol 35:549-554

Zeng ZN, Li FX (1991) Ultrastructural studies on spermatogenesis of Cyclina sinensis. Acta Oceanol Sin 13:547-551

Zhang T, Yang XS, Liu BZ (2003) Primary study on modes of seed hard clam Mercenaria mercenaria (Linnaeus, 1758) culture in field. Oceanol Limnol Sin 34:142-149

Zhao ZJ, Li FX (1992) Ultrastructural studies of spermatogenesis in Paphia undulata. J Oceanogr Taiwan Strait 11:238-243

Zhu JQ, Yang WX (2004) Spermatozoon ultrastructure of Scapharca subcrenata and Barbatia virescens and its implications for evolutionary relationship in Arcidae. Zool Res 25:57-62 